\title{
MILIARY SHADOWS IN THE LUNGS DUE TO MICROLITHIASIS ALVEOLARIS PULMONUM
}

\author{
BY
}

\author{
M. J. GREENBERG \\ From the Manchester Chest Clinic
}

(RECEIVED FOR PUBLICATION NOVEMBER 12, 1956)

The following case report describes an uncommon condition in which calcium salts are deposited in the alveolar spaces in the lungs, and in which the most striking feature is the miliary mottling seen in the radiograph. The condition was first described in 1856 by Friedreich, but the name by which it is now known, "microlithiasis alveolaris pulmonum," was given to it by Ludwig Puhr in 1933. The condition is rare, there being at the time of writing only 16 other cases in the literature. Most of these are described by pathologists, and it is possible that if the condition is brought to the notice of chest physicians and radiologists, more cases will be brought to light, cases which at present may masquerade under the names of miliary tuberculosis, haemosiderosis, sarcoidosis, and other causes of miliary mottling.

\section{CASE Report}

A schoolboy, then aged 11, was first seen at the Manchester Chest Clinic in November, 1952, because of an abnormal radiograph observed by Dr. $R$. Walshaw, of the Mass Radiography Unit.

Figs. 1 and 2 show the radiographic appearance at this time. Both lung fields were covered throughout with pinhead-size mottled opacities, giving a generalized ground-glass appearance. The mottling was greatest at the lung roots, but extended right out to the periphery. The heart appeared normal in size, but there was a linear opacity along the left border of the heart shadow.

When first seen he was a healthy-looking boy, a little small for his age, his weight being $68 \frac{1}{2} \mathrm{lb}$. (31 kg.). He had virtually no symptoms. He had not suffered from any illnesses in the past. His father had died at the age of 36 from pneumonia and bronchitis, having suffered five previous attacks of pneumonia. The boy was cared for by his paternal grandmother, his mother having left the family early in his life. She had remarried and nothing was known about her medical history. There were no siblings. The grandmother has a normal chest radiograph.

On examination no clinical abnormality was discovered in any of the systems. The Mantoux test was negative to $0.1 \mathrm{ml}$. of $1 / 1,000$ (10 T.U.) but positive to $1 / 100$ (100 T.U.).

Despite his apparent good health it was considered that further investigations were advisable, and he was admitted for observation to the Royal Manchester Children's Hospital. While he was there he remained well, his temperature being normal throughout. The E.S.R. was $5 \mathrm{~mm}$. in one hour, the blood pressure was normal, and the bone marrow was normal. A gastric lavage culture was negative for tubercle bacilli. Radiographs of all the long bones were normal. The total serum proteins were $7.23 \mathrm{~g}$. (albumin $4.44 \mathrm{~g}$. and globulin 2.79 g. per $100 \mathrm{ml}$.).

It was at first thought that he might be suffering from chronic miliary tuberculosis, but this diagnosis was discarded and he was discharged with a tentative diagnosis of sarcoidosis.

At the Chest Clinic it was considered that he was more likely to have idiopathic pulmonary haemosiderosis, although the haemoglobin remained high

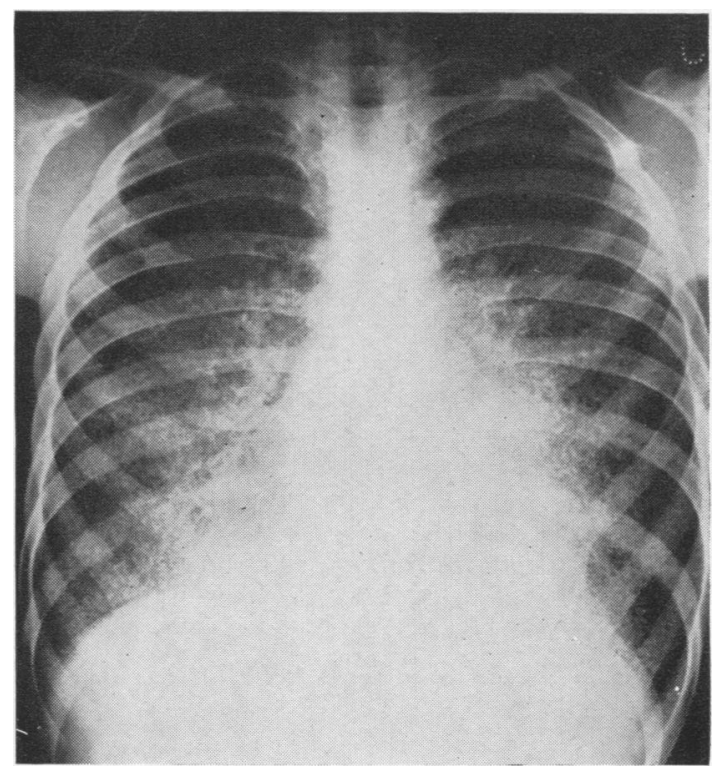

FIG. 1.-Postero-anterior radiograph of the chest. 


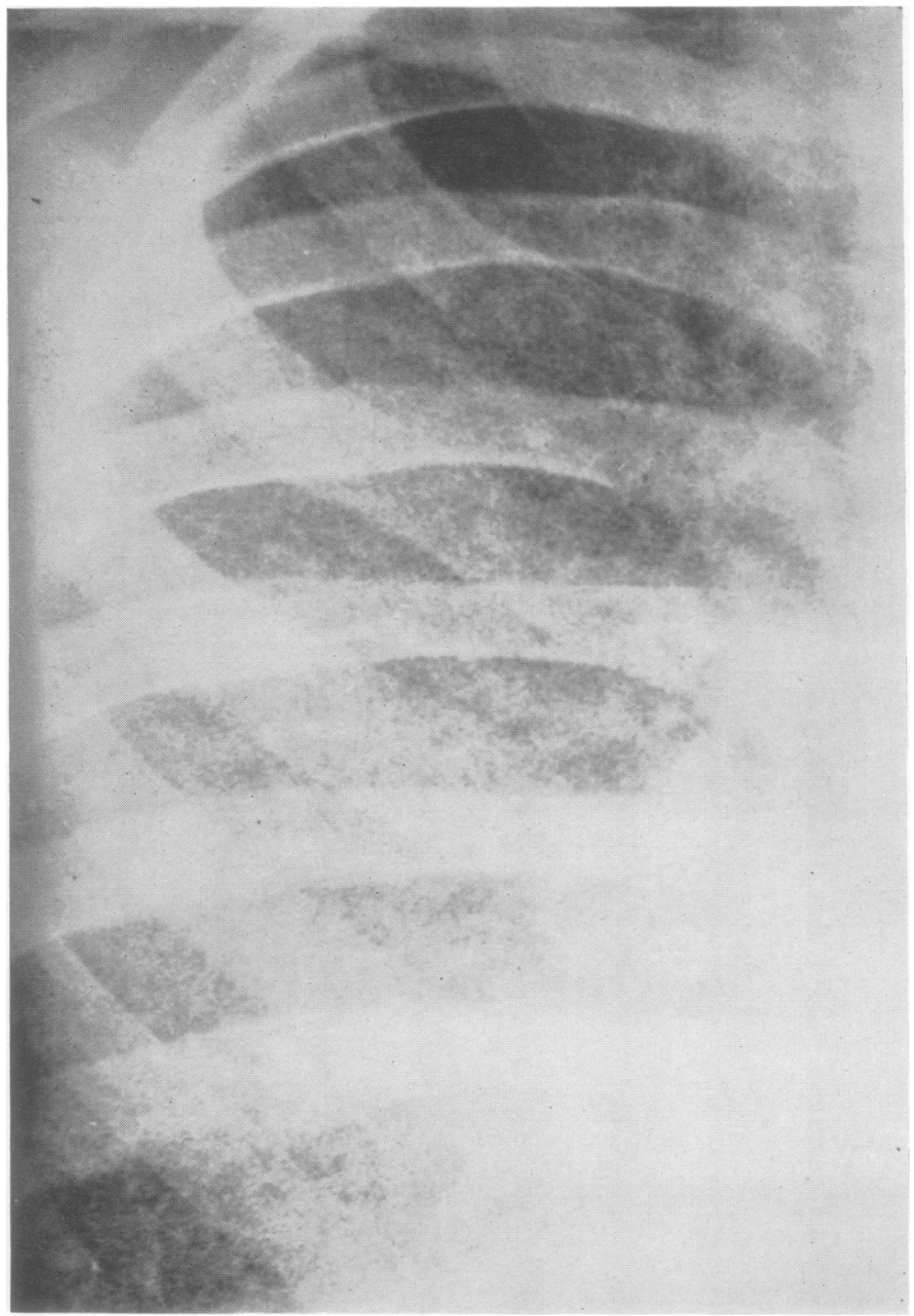

FIG. 2.-Part of the right lung field, less reduced.

and he did not have any bleeding episodes. This diagnosis was agreed upon by various chest physicians and radiologists, and the boy was kept under periodic observation for over three years.

During this time he remained well, his weight increasing by nearly 3 st. to 6 st. $8 \mathrm{lb}$. (41 kg.). His chest radiograph remained completely unaltered.

In March, 1956, it was considered that further investigation was justified. The boy was due to leave school, and it was impossible to give a prognosis without further information.

Accordingly he was admitted to the Park Hospital, Davyhulme, Manchester. He was symptom-free and his vital capacity was $2,300 \mathrm{ml}$. Under general anaesthesia a right thoracotomy was performed and a biopsy was taken from the middle lobe. The lung felt normal, but when attempts were made to cut sections, this was impossible because of the presence of 
numerous hard white gritty particles. Part of the specimen was then decalcified and the decalcified sections showed laminated microliths or calcospherites lying within the lumina of most of the alveoli (Fig. 3).

These microliths gave the reactions for calcium of Von Kossa's and Langeron's alizarin red S tests. By spectroscopy at the Department of Petrology, Manchester University, the material was shown to be calcium phosphate. They occurred in about half of the alveoli, the remaining alveoli being apparently normal. In some cases they fitted the alveoli closely, in others they appeared to have shrunk away from the walls. They appear to be made of concentric laminations. There was no inflammatory reaction in the sections examined, except that the microliths were surrounded by an incomplete layer of macrophages. There was a striking lack of fibrosis.

Following upon this finding, various other investigations were undertaken to discover whether there was a general disturbance of calcium metabolism; but these all proved to be essentially normal, the figures being : serum calcium $10.4 \mathrm{mg}$., inorganic phosphate $4.3 \mathrm{mg}$., protein $7.2 \mathrm{~g}$. (albumin $4 \mathrm{~g}$., globulin $3.2 \mathrm{~g}$.) ; alkaline phosphatase 13 units ; blood urea $24 \mathrm{mg}$. per $100 \mathrm{ml}$. ; urea clearance $75 \%$; urine calcium $370 \mathrm{mg}$., inorganic phosphorus $990 \mathrm{mg}$. in a 24-hour specimen. Urine concentration and dilution tests were normal. The sputum was repeatedly examined for microliths with negative results.

Convalescence from the operation was uneventful, and the boy was discharged to periodic surveillance.

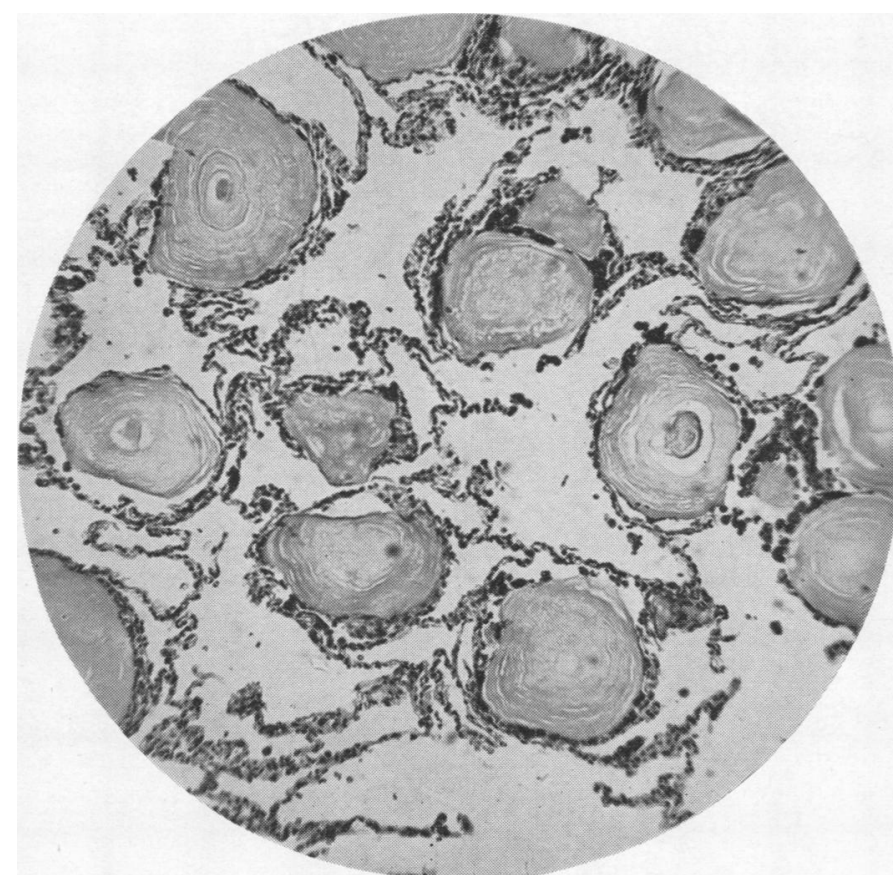

FIG.3.-Histology of the biopsy specimen of lung. Haematoxylin and eosin, $\times 100$.

\section{Discussion}

This type of pulmonary microlithiasis has previously been described, although most cases have been diagnosed only after death, and so far in the literature there are only two other cases, one in Hungary (Petrányi and Zsebök, 1954) and one in the U.S.A. (Kent, Gilbert, and Meyer, 1955), in which the diagnosis has been histologically proved during life.

The name "microlithiasis alveolaris pulmonum" was first given to the condition in 1933 by Ludwig Puhr. However, as far back as 1856 three cases of "corpora amylacea" of the lungs were reported by Friedreich, and from the description it is probable that one of them was the same as the present case. Corpora amylacea, as usually described, differ from the microliths in this case in that they give a positive stain for amyloid and occur in affected parts of the lungs, usually in conditions such as emphysema and chronic bronchitis.

In most of the other cases reported the disease was confined to the lungs, though in one (Badger, Gottlieb, and Gaensler, 1955) there was also a history of recurrent renal and ureteric calculi, and several stones were found in the kidneys at necropsy. The consensus of opinion is that in the lungs calcium phosphate is deposited around the cells of an alveolar exudate.

The cause of the deposition is not known, but it is suggested that it is more likely to occur in tissues where the reaction is alkaline, such as the lungs, stomach, and kidneys. According to Wells (1911), these three organs excrete acids-carbon dioxide from the lungs, hydrochloric acid from the stomach, and acid sodium phosphate from the kidneys - in consequence of which the parenchymal tissues are relatively alkaline. The higher the carbon dioxide content of the blood, the higher the concentration of calcium salts in the form of soluble carbonates might be. Reduction of carbon dioxide with the appearance of relative alkalinity might cause a deposition of calcium in normal tissues of the lungs. Wells reported 29 cases of metabolic deposition of calcium in otherwise normal lungs, stomachs, and kidneys, but 25 of these also showed disease of the bones, whereas there is no such evidence in the rest of the reported 
cases of microlithiasis alveolaris pulmonum. Nevertheless, some metabolic alteration in the acid-base relation does seem a reasonable explanation for the deposition of calcium in apparently normal tissues.

In several of the cases reported there was a history of recurrent attacks of pneumonia, and in at least two there was associated mitral stenosis.

The sex distribution has been approximately equal. With regard to age, the disease has been reported from 8 to 72 years. Most of the cases diagnosed were about 40 years old at diagnosis, although of course the disease may have been present for many years. Death usually occurred between the ages of 30 and 50 , the average being 40 , and was usually preceded by increasing dyspnoea and attacks of cardiac failure. From the small number of cases reported, the disease appears to be slowly progressive, but the present case, in which there has been no clinical or radiological change during the past four years, suggests that some additional factor is needed to start the progression. In the more advanced cases (Sharp and Danino, 1953), as well as the calcification there is actually some ossification.

Kent and others (1955) suggest that the disease is the result of a peculiar exudative response to a variety of insults such as mitral stenosis, recurrent pneumonia, and exposure to dust. However, in the present case there have been no such insults, and it may be that the disease is already present and remains stationary until such additional irritation or insult causes it to progress.
With regard to prognosis, almost all the observed cases have proved fatal, though one was observed for the long period of 25 years. Death rarely seems to occur before the age of 40 , and in the present case it seems reasonable to offer an expectation of at least another 25 years.

As far as treatment is concerned, none is known. It is interesting to speculate whether the microliths could be dissolved by inhalations of carbon dioxide, for example, but for practical purposes all that can be done is to treat the late dyspnoea and cardiac failure symptomatically.

\section{SUMMARY}

A case is described of alveolar deposition of calcium phosphate in the lungs, diagnosed by lung biopsy. The aetiology of the condition is discussed.

My thanks are due to Mr. Peter Jones for performing the lung biopsy, to Dr. K. Daber for the pathological report, to Dr. L. Doyle, whose knowledge of the literature enabled the diagnosis to be made early, and to Miss Gibbon, of the Department of Medical Photography, Wythenshawe Hospital, for the illustrations.

\section{REFERENCES}

Badger, T. L., Gottlieb, L., and Gaensler, E. A. (1955). New Engl. J. Med., $253,709$.

Friedreich, N. (1856). Virchows Arch.path. Anat., 9, 613; and 10, 507 Kent, G., Gilbert, E. S., and Meyer, H. H. (1955). A.M.A. Arch. Path., 60, 556.

Petrányi, G., and Zsebök, Z. (1954). Radiol. clin. (Basel), 23, 202. Puhr, L. (1933). Virchows Arch. path. Anat., $290,156$.

Sharp, M. E., and Danino, E. A. (1953). J. Path. Bact., 65, 389 Wells, H. G.( 1911). Arch. intern. Med., 7, 721. 